\title{
The Role of Faithfulness in Imperfect Overlapping in Korean Blends: A Nonce Word Study
}

\author{
Suzy Ahn \\ New York University
}

\section{Introduction}

I report on a nonce word study of imperfect overlapping in Korean blends where Korean speakers rated blends with various pairs of segments in a possible overlapping position (e.g. kata + pami $=$ katami). The results show that Korean speakers have a preference towards blends with segments with a laryngeal feature difference $\left(/ \mathrm{p} / \mathrm{vs} . / \mathrm{p}^{\mathrm{h}} /\right)$ as overlapping segments in comparison to pairs with a place $(/ \mathrm{p} /$ and $/ \mathrm{k} /)$ or manner $(/ \mathrm{p} /$ and $/ \mathrm{m} /)$ feature differences. Moreover, Korean speakers preferred blends that retained more prominent features. When fortis/aspirated stops are in competition with lenis stops (e.g. kat ${ }^{\mathbf{h}} \mathbf{a}+\underline{\text { tami)}}$ ), the resultant blends with fortis/aspirated stops are rated higher (kat ${ }^{\mathbf{h}}$ ami is rated higher than katami).

I argue that these preferences arise from the faithfulness rankings required in the phonology of Korean. They do not require a construction-specific grammar just for blends. When a given morpheme alternates between two phonological forms, it is often observed that the alternation is phonologically minimal, involving relatively few features. As a result, the segment 'similar' to the input segment is most likely to be chosen as an output. Korean phonological alternation is interesting in that while manner, place, and laryngeal features alternate in coda position, only the laryngeal feature can alternate in onset position where lenis stops become fortis or aspirated stops based on the preceding segments. For example, a verb particle $|-t a|$ 'to' can be either a lenis, aspirated, or fortis stop based on the preceding segments. ( $\operatorname{coh}+\underline{t} a \rightarrow \cot ^{h} a$ 'to like', $i p+\underline{t} a \rightarrow i p \underline{\underline{*}} a$ 'to wear', $h a+\underline{t} a \rightarrow h a \underline{t} a$ 'to do') ${ }^{1}$. The existing alternations in real Korean words support a higher weighting for place/manner feature faithfulness over laryngeal faithfulness. I show the grammar used for imperfect overlapping reflects speakers' knowledge of the native grammatical alternations with a Max-Ent grammar (Wilson, 2006). This study shows how the choices Korean speakers make in a nonce word task of imperfect overlapping bear on language general phonology rather than a construction-specific knowledge of phonology.

\section{Korean lexical blends and imperfect overlapping}

Blending is a word-formation process in which two independent words are merged into a new word with shortening of at least one of the source words (Hebrew (Bat-El, 1996), Spanish (Piñeros, 2004), English (Gries, 2004; Hong, 2005), Korean (Ahn, 2014). One of the main characteristics of blending is overlapping, as in the example 'motel $=($ motor + hotel $)$,' in which $/ t /$ is a segment from both 'motor' and 'hotel'. A Korean example of overlapping is shown in (1). Korean blends take the initial segmental sequence of the first source word ( $\mathrm{cam}$ ) and the prosody, in the form of the number of syllables, from the second source word (symposium), and ' $\mathrm{m}$ ' is an overlapping segment.

$$
\begin{aligned}
& \text { camp } p^{h} \text { ocism }=c a \underline{\boldsymbol{m}}+\left(\text { si) } \underline{\boldsymbol{m}} p^{h}\right. \text { ocism } \\
& \text { "a symposium that is really boring" ('a sleep'+'a symposium') }
\end{aligned}
$$

\footnotetext{
* I'd like to thank Maria Gouskova, Gillian Gallagher, Frans Adriaans, Lisa Davidson, Dániel Szeredi, Emily Nguyen, and the NYU PEP Lab members.

${ }^{1}$ From now on, ${ }^{\text {h' }}$, in $/ \mathrm{k}^{\mathrm{h}} /$ represents an aspirated stop, and ' $*$ ' in $/ \mathrm{k}^{*} /$ represents a fortis stop.
} 
Bat-el (1996) and Piñeros (2004) propose output-output correspondence constraints (McCarthy \& Prince, 1995) between each source word of a blend and the resultant blend. Subsequently, the faithfulness requirements of each source word, such as segmental or prosodic structure maximization, are in competition. For example, the head source word of the blend usually corresponds to the blend with respect to its prosodic structure, but segmental maximization of the head may be violated in the initial part of the blend. The following is the correspondence relation for the blend in (1):

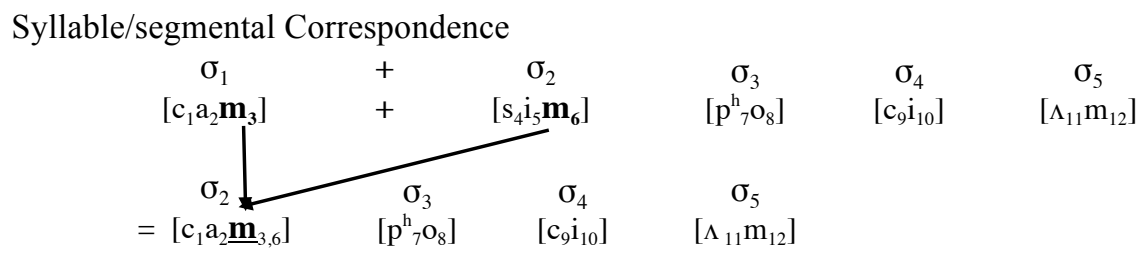

Several interesting exceptional patterns in which segmental faithfulness is preferred to prosodic faithfulness have been observed (Ahn, 2014), as shown in (3) and (4). In exceptional cases, the resultant blend has one more syllable than the head because more segments from two source words can be preserved; this is possible due to the overlapping segments 'ne' in (3). In order to understand the intended meaning of a blend, both of its source words need to be recovered effectively by language users (Lehrer, 1996; Piñeros, 2004; Bat-El, 2006). Recoverability of the source words is high when their similarity to the blend is high. This leads to the assumption that phonological characteristics of the blends are adopted to enhance the similarity between the blend and its source words. For this purpose, segmental and prosodic characteristics of blending conflict with each other. Blends usually have an overlapping segment, and segments participating in overlapping should be identical or at least similar to each other.

$$
\begin{aligned}
& \text { tone } t^{h} \text { icin }=\text { tone }(i \operatorname{sj} \wedge n)+\underline{\boldsymbol{n e}} t^{h} \text { icin } \\
& \text { "a netizen who donates" ('donation'+'netizen') }
\end{aligned}
$$

A similar analysis can be provided for the imperfect overlapping cases like example (4).

$$
\begin{aligned}
& \text { a. } t^{h} \varepsilon \underline{\boldsymbol{k}^{h}} \text { oliın }=t^{h} \varepsilon\left(\underline{\boldsymbol{k}^{*}} \text { wanto }\right)+\underline{\boldsymbol{k}}^{\boldsymbol{h}} \text { olis } n \\
& \text { "a mixture of Taekwondo and Korean" ('Taekwondo'+'Korean language') }
\end{aligned}
$$

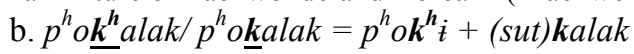

$$
\begin{aligned}
& \text { "a spork" ('a fork' + 'a spoon') }
\end{aligned}
$$

It seems that $/ \mathrm{k}^{\mathrm{h}} /$ in blend $\left(4 \mathrm{a}\right.$ ) corresponds to both $/ \mathrm{k} /$ and $/ \mathrm{k}^{\mathrm{h}} /$ in each source word. The corresponding segments, $/ \mathrm{k} /$ and $/ \mathrm{k} /$, are not completely identical, but they are considered to be overlapping segments. In this case, faithfulness of segments from both source words was preserved, but a feature identity from one segment (in case of (4a), a fortis feature of the $/ \mathrm{k} /$ from the left source word) is violated (McCarthy \& Prince, 1995; Piñeros, 2004). The variation of blends with both $/ \mathrm{k} /$ and $/ \mathrm{k}^{\mathrm{h}} /$ are shown for (4b).

Among the 493 Korean blends in my corpus, 233 have a possible overlapping position. This possible overlapping position is where the first word ends and the second word starts; consonants from both source words can occupy that position, but only a segment from one source word seems to survive in the blend

\begin{tabular}{|c|c|c|c|c|}
\hline differ in & laryngeal feature & place feature & manner feature & more than two features \\
\hline \# & 23 & 22 & 23 & 79 \\
\hline Examples & 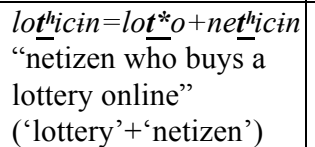 & $\begin{array}{l}p^{h} \wedge p^{h i c i n}=p^{h} \wedge p^{h} i+n e t^{h} i c i n \\
\text { "a netizen who likes a } \\
\text { puppy" } \\
\text { ('puppy'+ 'netizen') }\end{array}$ & $\begin{array}{l}\text { pinema }=\text { piti.o }+ \text { sinema } \\
\text { "video and cinema" } \\
\text { ('a video' + 'a cinema') }\end{array}$ & $\begin{array}{l}k^{h} \text { omelik } k^{h} a=k^{h} \text { oli.a+amelik }{ }^{h} a \\
\text { "Korea and America" } \\
\text { ('Korea' + 'America') }\end{array}$ \\
\hline
\end{tabular}
output. Examples in (5) show different mismatching segments in possible overlapping position. The overlapping position and relevant segments from both words are underlined.

(5) Blends with mismatching segments in 'possible overlapping position' 
The phenomenon has been reported in other languages such as Spanish and English (Kelly, 1998; Gries, 2004; Piñeros, 2004). For example, in Spanish, [čàn.da.fé] 'Santafé with the connotation that it is a lousy soccer team' ([čán.da] 'lousy' + [sàn.ț.fé] 'a soccer team of Bogotá') is a blend with imperfect overlapping where [d] and [t] are overlapping segments that differ from each other in voice feature specification. A similar case in English is "Clantastical (clandestine+fantastical)," where two segments in the overlapping position are also different in voicing, [d] and [t] (Kelly, 1998). Imperfect overlapping has been mentioned as a phenomenon related to phonological similarity (Algeo, 1977; Kelly, 1998; Gries, 2004), but has not been studied thoroughly.

What segments can coalesce with each other, and further, which segment is likely to survive in the resultant blend? Also, while blending has construction-specific phonology, does this grammar govern imperfect overlapping or is imperfect overlapping based on language general phonology? There are not enough attested blends with imperfect overlapping to really explore what counts as a good or bad overlap. Nonce word tasks allow us to collect more data, and to gauge what is most productive.

\section{The design of the study}

3.1 Introduction This experiment is designed to test what governs the acceptability of imperfect overlapping. The linguistic factors related to blending are not only phonological, but blends are also affected by semantics. Usually the semantic head goes to the right side, determining the prosodic structure of the blend. According to positional faithfulness (Beckman, 1997), more segments are preserved from the head of the blend than the non-head (Shaw et al., 2014). For the current study, I use nonce words to focus on the phonological factors. In this case, headedness will be irrelevant because there is no semantics.

3.2 Hypotheses The first hypothesis is that Korean speakers are using the faithfulness constraints they acquired from their native language when encountering imperfect overlapping. Korean shows phonological alternations in place, manner, and laryngeal features, but only laryngeal features can alternate in onset positions. If the results of a nonce word study can be explained within a Korean alternation grammar, it shows that people are using grammatical knowledge when they decide whether two segments can imperfectly overlap or not. On the other hand, if Korean speakers are using construction-specific grammar for imperfect overlapping in blend, the results will show different patterns from Korean alternation grammar, such as speakers tolerating segments with a place feature difference in onset position.

The second hypothesis is that phonological similarity between two segments in the source words predicts the acceptability of the resultant blend. Previous studies reported that imperfect overlapping is related to the similarity of two segments (Algeo, 1977; Kelly, 1998; Gries, 2004). Among them, Kelly (1998) tried to construct a measure of phonological similarity between relevant consonants using a sonority hierarchy ${ }^{2}$. Similarity is determined in two different ways in this study: feature counting and shared-natural classes. Feature counting is one way to measure similarity based on how many features may be different between two segments in the source words. Two ways of counting features (the number of features and the type of features) were used in the current study.

Another measure for similarity is based on shared natural classes. The similarity matrix based on natural classes counts how many shared natural classes two segments have (the number of shared natural classes of two segments are divided by the sum of shared natural classes and non-shared natural classes) (Frisch et al., 2004). A shared-natural classes analysis highly depends on the feature system of one language. I employ the revised version of Cho (2012) as a feature system of Korean.

\subsection{Methods}

3.3.1 Materials and design Among Korean consonants, I focus on 11 Korean stops, as shown in Table (6). Korean has a unique laryngeal contrast of three voiceless stops, namely lenis, fortis, and aspirates.

\footnotetext{
${ }^{2}$ Kelly (1998:587) 'A measure of phonological similarity between the relevant consonants had to be constructed. Each consonant was given an integer score between 1 and 7 corresponding with its location in the following sonority hierarchy: (1) unvoiced stops, (2) voiced stops, (3) unvoiced fricatives and affricates, (4) voiced fricatives and affricates, (5) nasals, (6) liguids, and (7) glides.'
} 
Consonants for the experiment

\begin{tabular}{|l|l|l|l|l|}
\hline & & labial & alveolar & velar \\
\hline \hline Stop & Lenis & $\mathrm{p}$ & $\mathrm{t}$ & $\mathrm{k}$ \\
& Fortis & $\mathrm{p}^{*}$ & $\mathrm{t}^{*}$ & $\mathrm{k}^{*}$ \\
& Aspirated & $\mathrm{p}^{\mathrm{h}}$ & $\mathrm{t}^{\mathrm{h}}$ & $\mathrm{k}^{\mathrm{h}}$ \\
\hline Nasal & & $\mathrm{m}$ & $\mathrm{n}$ & \\
\hline
\end{tabular}

The 11 consonants above are similar or different from each other in terms of place (labial/coronal/dorsal), manner (oral/nasal), and laryngeal (lenis/fortis/aspirated) feature specification. In terms of feature counting, a consonant in the table can be different in either one feature or two features from other consonants. For example, the labial lenis stop $/ \mathrm{p} /$ is different from five consonants based on one feature. It is different in place feature specification from $/ \mathrm{t} /$ and $/ \mathrm{k} /$, in manner from $/ \mathrm{m} /$, and in laryngeal feature from $/ \mathrm{p}^{\mathrm{h}} /$ and $/ \mathrm{p}^{*} /$. Also, $/ \mathrm{p} /$ has five consonants that differ in two features. It is different in place and manner feature from $/ \mathrm{n} /$, and different in place and laryngeal feature from $/ \mathrm{t}^{\mathrm{h}} /, \mathrm{t}^{*} /, / \mathrm{k}^{\mathrm{h}} /$, and $/ \mathrm{k}^{*} /$.

In terms of types of features, there are six conditions: 0 (identical), 1 laryngeal $(1 \mathrm{~L}), 1$ manner $(1 \mathrm{M}), 1$ place (1P), 2 place \& manner (2PM), and 2 laryngeal \& place (2LP) features. The number of pairs per condition can be calculated based on the number of consonants in each feature. For example, there are nine pairs that differ in laryngeal feature because there are three laryngeal features (lenis, fortis, aspirated) and three different consonants based on each place feature (labial, coronal, dorsal). Table (7) shows the similarity matrix of 11 Korean consonants. Two identical consonants are denoted by ' 0 ,' ' 1 ' means that there is one feature difference between two consonants, and ' 2 ' means that there are two feature differences between two consonants. ' $1 \mathrm{P}$ ' means two consonants are different in place feature, ' $1 \mathrm{M}$ ' means manner feature, and ' $1 \mathrm{~L}$ ' means laryngeal feature, respectively.

(7) Similarity Matrix for stimuli

\begin{tabular}{|c||ccccccccccc|}
\hline & $\mathrm{p}$ & $\mathrm{p}^{\mathrm{h}}$ & $\mathrm{p}^{*}$ & $\mathrm{t}$ & $\mathrm{t}^{\mathrm{h}}$ & $\mathrm{t}^{*}$ & $\mathrm{k}$ & $\mathrm{k}^{\mathrm{h}}$ & $\mathrm{k}^{*}$ & $\mathrm{~m}$ & $\mathrm{n}$ \\
\hline \hline $\mathrm{p}$ & 0 & $1 \mathrm{~L}$ & $1 \mathrm{~L}$ & $1 \mathrm{P}$ & 2 & 2 & $1 \mathrm{P}$ & 2 & 2 & $1 \mathrm{M}$ & 2 \\
$\mathrm{p}^{\mathrm{h}}$ & $1 \mathrm{~L}$ & 0 & $1 \mathrm{~L}$ & 2 & $1 \mathrm{P}$ & 2 & 2 & $1 \mathrm{P}$ & 2 & $1 \mathrm{M}$ & 2 \\
$\mathrm{p}^{*}$ & $1 \mathrm{~L}$ & $1 \mathrm{~L}$ & 0 & 2 & 2 & $1 \mathrm{P}$ & 2 & 2 & $1 \mathrm{P}$ & $1 \mathrm{M}$ & 2 \\
$\mathrm{t}$ & $1 \mathrm{P}$ & 2 & 2 & 0 & $1 \mathrm{~L}$ & $1 \mathrm{~L}$ & $1 \mathrm{P}$ & 2 & 2 & 2 & $1 \mathrm{M}$ \\
$\mathrm{t}^{\mathrm{h}}$ & 2 & $1 \mathrm{P}$ & 2 & $1 \mathrm{~L}$ & 0 & $1 \mathrm{~L}$ & 2 & $1 \mathrm{P}$ & 2 & 2 & $1 \mathrm{M}$ \\
$\mathrm{t}^{*}$ & 2 & 2 & $1 \mathrm{P}$ & $1 \mathrm{~L}$ & $1 \mathrm{~L}$ & 0 & 2 & 2 & $1 \mathrm{P}$ & 2 & $1 \mathrm{M}$ \\
$\mathrm{k}$ & $1 \mathrm{P}$ & 2 & 2 & $1 \mathrm{P}$ & 2 & 2 & 0 & $1 \mathrm{~L}$ & $1 \mathrm{~L}$ & 2 & 2 \\
$\mathrm{k}^{\mathrm{h}}$ & 2 & $1 \mathrm{P}$ & 2 & 2 & $1 \mathrm{P}$ & 2 & $1 \mathrm{~L}$ & 0 & $1 \mathrm{~L}$ & 2 & 2 \\
$\mathrm{k}^{*}$ & 2 & 2 & $1 \mathrm{P}$ & 2 & 2 & $1 \mathrm{P}$ & $1 \mathrm{~L}$ & $1 \mathrm{~L}$ & 0 & 2 & 2 \\
$\mathrm{~m}$ & $1 \mathrm{M}$ & $1 \mathrm{M}$ & $1 \mathrm{M}$ & 2 & 2 & 2 & 2 & 2 & 2 & 0 & $1 \mathrm{P}$ \\
$\mathrm{n}$ & 2 & 2 & 2 & $1 \mathrm{M}$ & $1 \mathrm{M}$ & $1 \mathrm{M}$ & 2 & 2 & 2 & $1 \mathrm{P}$ & 0 \\
\hline
\end{tabular}

All 11 consonants are paired with each other. There are 66 pairs in total. In the experiment, two words consisting of two syllables will be given, and these words will be combined into a single word (blend) consisting of three syllables, as in (8). The onset of a second syllable of the left word and the onset of the first syllable of the right word are in competition for one position in the resultant blend, namely the onset of the second syllable of the blend. I will use the example of the pair $\left\{\mathrm{p}, \mathrm{p}^{\mathrm{h}}\right\}$.

$$
\begin{aligned}
& \operatorname{cop} \mathbf{u}+\mathbf{p}^{\mathrm{h}} u k o=\text { copuko vs. } \operatorname{cop}^{\mathrm{h}} u \mathrm{uko}^{3} \\
& \text { to } \mathbf{p}^{\mathrm{h}} \mathrm{u}+\mathbf{p} \text { puco }=\text { to } \mathbf{p}^{\mathrm{h}} u c o \text { vs. topuco }
\end{aligned}
$$

In example (8), there are two possible candidate blends, 'copuko' and 'cophuko,' when 'copu' and ' $\mathbf{p}^{\mathrm{h}} \mathrm{uko}$ ' blend with each other. While example (8) is a case where $/ \mathrm{p} /$ is in the left word and $/ \mathrm{p}^{\mathrm{h}} /$ is in the right word, with the $\left\{\mathrm{p}, \mathrm{p}^{\mathrm{h}}\right\}$ pair, a different order is also possible, where $/ \mathrm{p}^{\mathrm{h}} /$ is in the left source word, and $/ \mathrm{p} /$ is in the

\footnotetext{
3 'c' stands for a voiceless post-alveolar affricate in Korean.
} 
right source word as in the example (9). In other words, given a pair of two consonants, there are four possible combinations, based on (i) which consonant will be in left source word or right source word, and (ii) which consonants will survive in the blend. In terms of the $\left\{\mathrm{p}, \mathrm{p}^{\mathrm{h}}\right\}$ pair, four possible combinations can be summarized as follows:

(10) Four possible combinations of $\left\{\mathrm{p}, \mathrm{p}^{\mathrm{h}}\right\}$

\begin{tabular}{|l|l|l|l|}
\hline $\mathrm{p}+\mathrm{p}^{\mathrm{h}}=\mathrm{p}$ & $\mathrm{p}+\mathrm{p}^{\mathrm{h}}=\mathrm{p}^{\mathrm{h}}$ & $\mathrm{p}^{\mathrm{h}}+\mathrm{p}=\mathrm{p}^{\mathrm{h}}$ & $\mathrm{p}^{\mathrm{h}}+\mathrm{p}=\mathrm{p}$ \\
\hline
\end{tabular}

The combinations in (10) can test whether participants prefer a consonant with a certain feature, and if there is any positional effect, whether people prefer consonants from the left or the right source word.

To keep the experiment running time under 15 minutes, a structured subset of test items was presented. The total number of items in the trial is 62. The breakdown of each category and example is shown in (11).

(11) Structure of stimulus subsets

\begin{tabular}{|c|c|c|c|c|c|c|c|c|}
\hline Condition & $\begin{array}{l}\text { \# of } \\
\text { Pairs }\end{array}$ & $\begin{array}{l}\text { Example } \\
\text { (Pair) }\end{array}$ & LeftWord & RightWord & Candidate1 & Candidate2 & $\begin{array}{l}\text { Total \# of } \\
\text { source } \\
\text { word pairs }\end{array}$ & $\begin{array}{l}\text { \# of items } \\
\text { presented to } \\
\text { each person }\end{array}$ \\
\hline 0 & 11 & $\{\mathrm{p}, \mathrm{p}\}$ & topa & pako & \multicolumn{2}{|c|}{ topako } & 11 & 3 \\
\hline \multirow[t]{4}{*}{ 1laryngeal } & \multirow[t]{4}{*}{9} & \multirow[t]{4}{*}{$\mathrm{p}, \mathrm{p}^{\mathrm{h}}$} & copa & $\mathbf{p}^{\mathbf{h}_{\text {aso }}}$ & copaso & $\operatorname{cop}^{\mathbf{h}_{\text {aso }}}$ & \multirow[t]{4}{*}{36} & \multirow{4}{*}{$\begin{array}{l}16 \\
\text { (4 pairs) }\end{array}$} \\
\hline & & & topu & $\mathbf{p}^{\mathbf{h}}$ uco & top ${ }^{h}$ uco & topuco & & \\
\hline & & & $\operatorname{cip}^{h} u$ & puso & $\operatorname{cip}^{h}$ uso & cipuso & & \\
\hline & & & $\operatorname{mip}^{\mathbf{h}} \mathrm{a}$ & panu & $\operatorname{mip}^{\mathbf{h}}$ anu & mipanu & & \\
\hline \multirow[t]{4}{*}{ 1manner } & \multirow[t]{4}{*}{6} & \multirow[t]{4}{*}{$\mathrm{p}, \mathrm{m}$} & topa & maco & topaco & tomaco & \multirow[t]{4}{*}{24} & \multirow{4}{*}{$\begin{array}{l}12 \\
\text { ( } 3 \text { pairs) }\end{array}$} \\
\hline & & & nipu & muta & niputa & nimuta & & \\
\hline & & & $\operatorname{cimu}$ & put*o & cimut*o & ciput*o & & \\
\hline & & & koma & pali & komali & kopali & & \\
\hline \multirow[t]{4}{*}{ 1place } & \multirow[t]{4}{*}{10} & \multirow[t]{4}{*}{$\mathrm{p}, \mathrm{t}$} & mipu & tuka & mipuka & mituka & \multirow[t]{4}{*}{40} & \multirow{4}{*}{$\begin{array}{l}16 \\
\text { (4 pairs) }\end{array}$} \\
\hline & & & $\mathrm{t}^{\mathrm{h}}$ opa & taso & $\mathrm{t}^{\mathrm{h}}$ opaso & $\mathrm{t}^{\mathrm{h}}$ otaso & & \\
\hline & & & latu & puci & latuci & lapuci & & \\
\hline & & & muta & paku & mutaku & mupaku & & \\
\hline \multirow{2}{*}{$\begin{array}{l}\text { 2place- } \\
\text { laryngeal }\end{array}$} & \multirow[t]{2}{*}{18} & \multirow[t]{2}{*}{$\mathrm{p}, \mathrm{t}^{\mathrm{h}}$} & kopa & $\mathbf{t}^{\mathbf{h}_{\mathrm{ami}}}$ & kopami & $\operatorname{kot}^{\mathbf{h}_{a m i}}$ & \multirow[t]{2}{*}{36} & \multirow[t]{2}{*}{9} \\
\hline & & & $\operatorname{sot}^{h} u$ & pumo & sot $^{\text {h }}$ umo & sopumo & & \\
\hline \multirow{2}{*}{$\begin{array}{l}\text { 2place- } \\
\text { manner }\end{array}$} & \multirow[t]{2}{*}{12} & \multirow[t]{2}{*}{$\mathrm{p}, \mathrm{n}$} & kipa & naco & kipaco & kinaco & \multirow[t]{2}{*}{24} & \multirow[t]{2}{*}{6} \\
\hline & & & linu & puko & linuko & lipuko & & \\
\hline Total & 66 & & & & & & 171 & 62 \\
\hline
\end{tabular}

I limited the vowels after target consonants to /a/ and / $\mathrm{u} /$ because /i/ conditions palatalization in Korean, and balanced the appearance of two vowels throughout a test set. For example, given two $\left\{\mathrm{p}, \mathrm{p}^{\mathrm{h}}\right\}$ tokens, one had /a/, and the other had/u/.

3.3.2 Procedure The experiment was conducted online using the online experiment platform Experigen (Becker \& Levine, 2010). All items were written in Korean orthography. This was possible because Korean has a relatively straightforward mapping of phoneme to grapheme. Participants saw two source words and the possible blend, and were asked to rate each blend from 1 (worst) to 5 (best). Participants only saw one of the two candidate blends, and if they saw one blend form, they did not see the counterpart of that blend within the same trial.

The instructions to participants explained the concept of blending with attested Korean blends (e.g. $p^{h} \underline{\boldsymbol{k}}^{\boldsymbol{h}}$ alak "a spork" ( $p^{h} \underline{\boldsymbol{k}}_{\boldsymbol{i}}^{\boldsymbol{i}}$ 'a fork' + (sut) $\underline{\boldsymbol{k} a l a k}$ 'a spoon'). All trials were given with random dog pictures. Participants were informed that they would see two dog pictures with made-up names and were asked to imagine that if the two dogs were to have a puppy, what the name of the resulting puppy would be; an example in the real world is 'labrador + poodle = labradoodle.' Names of hybrid dog breeds are good examples of blending. Another benefit of dog pictures is that since there is no semantic head between two dog names, the effect of semantics can be completely eliminated. Dog pictures were shown to participants 
to motivate them to finish the task as well as to provide an idea of what blends are. ${ }^{4}$

Participants first saw the two nonce words with two random dog pictures, as in the left screen (12) below, and then on the next page, they saw the blend word without dog pictures as in the right screen. All experiment pages were used with Korean orthography; (12) is the English translation of the experiment pages. There were 62 trials in total, and a demographic survey at the end of the experiment.

(12) (translated) Trial pages

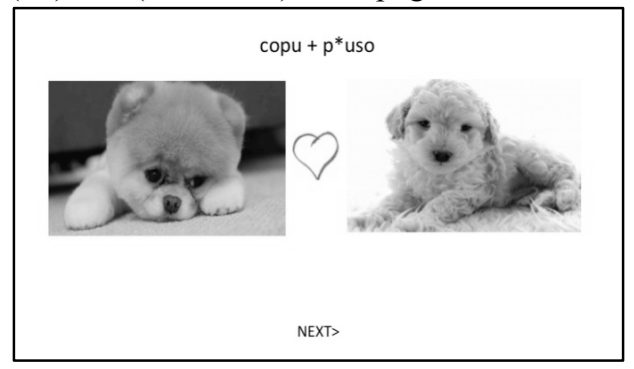

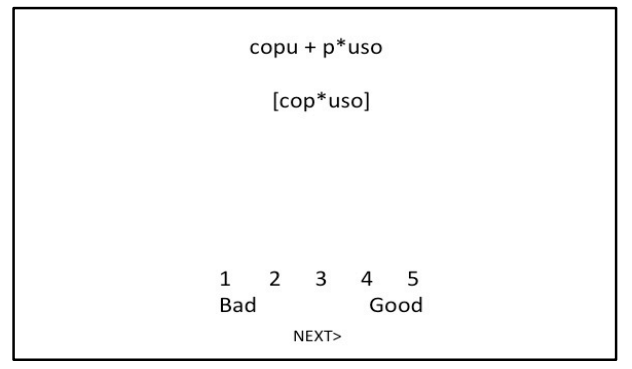

3.3.3 Participants All participants were self-reported native speakers of Korean. They were recruited via social networks with Korean advertisements. There were 275 participants, and 197 participants finished the experiment. Among them, 98 were female, and 82 were male; the rest of the participants did not specify their gender. Age ranged from 18 to 58 years, with a mean of 30.7 years.

\section{Results of the rating study}

For the analysis, I used the statistical program R (R Core Team, 2013), with the package lme4 (Bates et al., 2014), using a linear mixed model and lmertest to get the $p$-value for each factor. Among 197 participants who finished all 62 trials, I only analyzed the results of 190 participants whose standard deviation of the individual's mean rating was higher than 0.5. If a standard deviation of each participant's rating was less than 0.5 , it was considered as not performing the task but rather pushing only one button constantly.

In the experiment, I also controlled for the effect of position because there is a possibility that participants prefer the segments in the right source words as a default, and it is true when semantic constraints are considered (Shaw et al., 2014). However, no significant effect was found with the nonce word task. (Mean: left - 3.41 vs. right - 3.45).

4.1 Feature Differences The results of feature differences are shown with a beanplot, in Figure 1. I represent the beanplot for each condition based on the quantity and quality of the difference. The beanplot compares the distribution of different conditions; one bean represents one condition, and its distribution is a density shape. A horizontal bar indicates the mean of each bean, and a dotted line indicates the overall average of the rating, which is 3.48. This overall average rating is relatively high based on a 5-point scale because all of the blends are three syllables with one or two segments from each source word, which make most blends quite acceptable to some extent. There were no extremely unacceptable made-up blends in the experiment, for instance, a blend like ' $k i p a+$ pako=ko'.

As can be seen in Figure 1, identical segments such as /p/ in 'kipa+pako' were rated higher than any other condition. The acceptability of identical segments is significantly different from other conditions and rated much higher. This indicates that participants were actually doing the task correctly, and identical segments are different from 'similar' segments. The left beanplots (a) show the difference between 0 vs. 1 vs. 2 features and the right beanplots (b) show the difference between each condition. 1 feature difference rated higher than 2 features difference in (a), and among other conditions, one laryngeal feature difference ' $1 \mathrm{~L}$ ' $(\mathrm{M}=3.64)$ is rated higher than others in (b).

\footnotetext{
${ }^{4}$ I ran a pilot with 8 participants without any pictures, and participants reported they were not sure what they were doing with all the nonce words, and the experiment was boring and long. Thus, I included dog pictures for the real experiment.
} 
(a) Feature differences

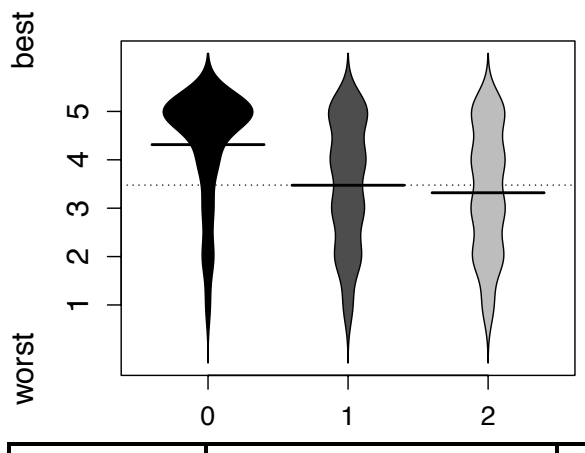

(b) Conditions

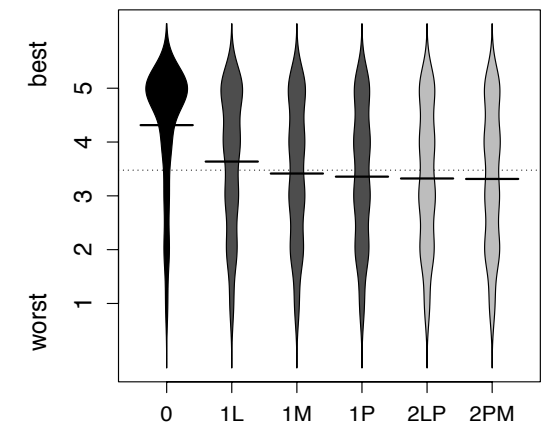

\begin{tabular}{|c|c|c|c|c|}
\hline Difference & Condition & item & Cand1 & Cand2 \\
\hline 0 (identical) & 0 (identical) & kipa+pako & \multicolumn{2}{|c|}{ kipako } \\
\hline \multirow[t]{3}{*}{1} & 1L (laryngeal) & kipa $+\mathbf{p}^{\mathrm{h}}$ ako & kipako & kiphako \\
\hline & $1 \mathrm{M}$ (manner) & kipa+mako & kipako & kimako \\
\hline & 1P (place) & kipa+tako & kipako & kitako \\
\hline \multirow[t]{2}{*}{2} & 2LP (laryngeal+place) & kipa+thako & kipako & kithako \\
\hline & 2PM (place+manner) & kipa+nako & kipako & kinako \\
\hline
\end{tabular}

Figure 1. Ratings based on the Feature difference and 6 conditions

The result is confirmed with the mixed effect model. Rating is the dependent variable, where the predictor is three different and six different conditions, respectively. Participants and items were entered as random factors. $P$-values were obtained with the package lmertest. In the model for Feature differences (a), 0,1 , and 2 differences are different from each other $(p<0.001)$, and in the model for Conditions (b), 1L was different from all other conditions $(p<0.001)$, whereas $1 \mathrm{M}$ and $1 \mathrm{P}$ are different from $1 \mathrm{~L}$, but not very different from 2LP or 2PM. However, it seems like the effect size of 1L is not as big as the difference between 0 and everything else. In the next section, the breakdown of 1L will show if speakers are sensitive to what segments to keep in the blend. For example, kipa+ $\mathbf{p}^{\mathbf{h}}$ ako, participants prefer one candidate (kiphako) over the other (kipako).

4.2 Laryngeal features: Salient segment Imperfect overlapping is not all about how similar two segments are. When two segments are competing with each other, the segment that survives among two segments is also crucial. For showing the salience of the segment/consonant (e.g. cupa+p*ako, are ratings of cupako and cup*ako different?), I tested just the subset of data that is different in the laryngeal feature (1L (cupa $\left.+\mathbf{p}^{*} \mathrm{uko}\right)$ and $2 \mathrm{LP}$ (cupa $+\mathbf{t}^{*}$ ako)). I made this subset because among 1 difference $(1 \mathrm{~L}, 1 \mathrm{M}$ and 1P) the result in section 4.1 showed that laryngeal feature differences are considered to be more acceptable than other features. Features $1 \mathrm{M}$ and $1 \mathrm{P}$, such as $\{\mathrm{p}, \mathrm{m}\}$ and $\{\mathrm{t}, \mathrm{p}\}$ pairs, were excluded. If segments in source words are too dissimilar (2LP), the preference for a certain segment in the resultant blend might not arise with the rating task because people already rate the blend as bad based on the similarity of the pairs.

The beanplot used in Figure 2 has two sides. The left side (black bean) shows the rating for 1L, and the right side (gray bean) shows the ratings for 2LP, which means that only the laryngeal feature is different for the black bean, whereas the laryngeal feature and place are different for the gray bean. Subsets of 1L (black bean) show that there is a preference for the aspirated or fortis stops over the lenis stop, as in Figure 2. Each bean shows what laryngeal feature is preserved in the blend form as an overlapping segment. For example,

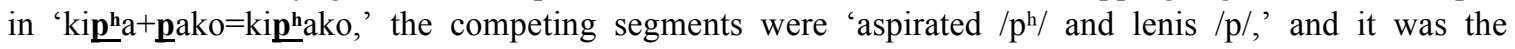
aspirated stop that survived in the blend.

As predicted, there is no preference for the aspirated/fortis stop over the lenis stop in blends when there is a place feature difference, as can be seen with the gray beans. The means of 1L and 2LP are different when the aspirated/fortis stop is in the resultant blend, but not different when the lenis stop is in the blend. Participants do not prefer segments to differ in place and laryngeal features regardless of the laryngeal feature of the segment in the resultant blend. Therefore, two conclusions can be made from the beanplot: (i) 
aspirated stops and fortis stops are preferred in the blend, when aspirated-lenis or fortis-lenis are in competition. (ii) However, the preference for aspirated or fortis stops is only found when segments from the source words differ from each other only in laryngeal feature.

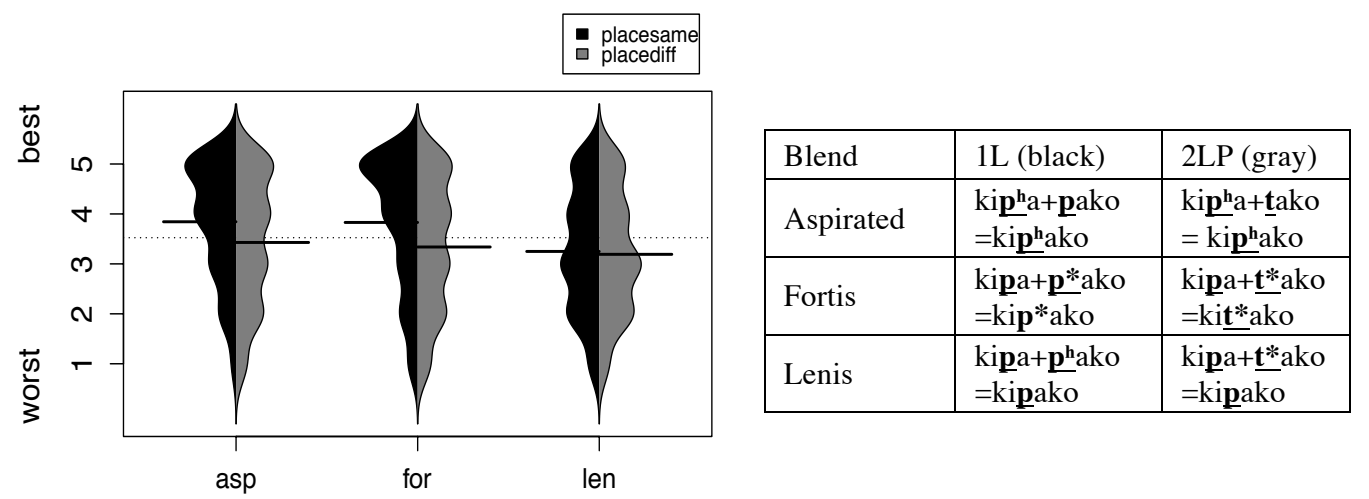

Figure 2. Laryngeal feature of the segment in the blend and 1P vs. 2LP

The linear mixed effect model in Table 1 confirms the effect. The dependent variable is rating. Predictors are the laryngeal specification of the overlap consonant in the blend and the existence of a place difference. The baseline for the intercept is $2 \mathrm{LP}$ with the aspirated stop in the blend. The intercept for baseline (2LP aspirated) is rated slightly higher than 2LP fortis $(p<0.05)$, and significantly higher for blend lenis.

The crucial part is when the baseline is compared to $1 \mathrm{~L}$. The effect of factor $1 \mathrm{~L}\left(\mathrm{kipa}+\mathbf{p}^{\mathrm{h} a k o}=\mathrm{kip}^{\mathrm{h}} \mathrm{ako}\right)$ is significantly different from the baseline (2LP aspirated, kita $+\mathbf{p}^{\text {hako }}=k^{2} \underline{p}^{\text {hako }}$ ). The interaction of $1 \mathrm{~L}$ and fortis is not significant, which means $1 \mathrm{~L}$ fortis $\left(\mathrm{kipa}^{+} \mathbf{p}^{*} \mathrm{ako}=\mathrm{kip}\right.$ *ako) and $1 \mathrm{~L}$ aspirated $\left(\mathrm{kipa}{ } \mathbf{p}^{\mathrm{h}} \mathrm{ako}=\mathrm{ki} \mathbf{p}^{\mathrm{h}} \mathrm{ako}\right)$ are not that different from each other. However, the interaction between $1 \mathrm{~L}$ and lenis is significant and the coefficient is negative, which implies a lower rating; 1L lenis $\left(\mathrm{kipa}+\mathbf{p}^{*}\right.$ ako $=$ kipako) is rated significantly lower than $1 \mathrm{~L}$ fortis or $1 \mathrm{~L}$ aspirated.

Model=lmer(rating Blary+Diff1+Blary:Diff1+(1+Blary+Diff1 lparticipant)+(1litem)

Number of items: 4747, Participants: 190

\begin{tabular}{|l|l|l|l|l|}
\hline & Estimate & Standard Error & $t$-statistics & $p$-value \\
\hline Intercept (aspirated, 2LP) & 3.4386 & 0.0778 & 44.222 & \\
\hline Blend: Fortis & -0.1188 & 0.0601 & -1.976 & 0.0488 \\
\hline Blend: Lenis & -0.2549 & 0.0770 & -3.309 & 0.0011 \\
\hline 1L True & 0.4079 & 0.0722 & 5.648 & 0.0001 \\
\hline Fortis: 1L & 0.0904 & 0.0843 & 1.073 & 0.2876 \\
\hline Lenis: 1L & -0.3655 & 0.0942 & -3.879 & 0.0003 \\
\hline
\end{tabular}

Table 1. Model for laryngeal feature of the blend, and existence of place differences

The results in Figure 1 and Table 1 show that there is a preference for the aspirated and fortis stop in comparison to the lenis stop. There are then two follow-up questions to be asked. First, is there a preference between two different salient segments? Second, is acceptability different when there is a lenis stop in a pair vs. only aspirated and fortis stops in a pair? In other words, are lenis-aspirated pairs or lenis-fortis pairs more acceptable than aspirated-fortis pairs?

Figure 3 shows that ratings are higher when there is a lenis in the pair given that the means for the gray beanplots are higher than black beanplots for both aspirated and fortis in the blend. There is no preference between blends with either aspirated or fortis stop (black bean plot). 


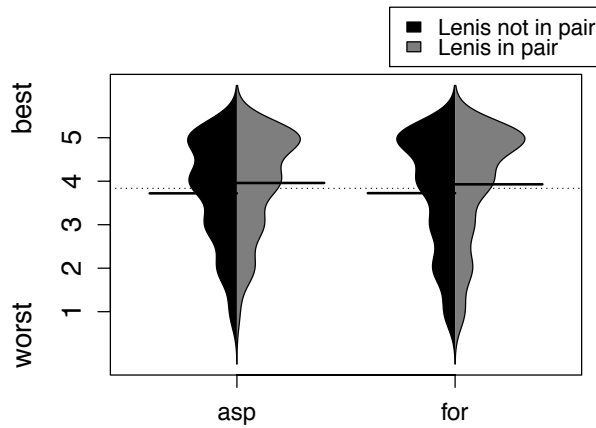

\begin{tabular}{|c|c|c|}
\hline Blend & No Lenis(black) & Yes Lenis(gray) \\
\hline Aspirated & $\begin{array}{l}\operatorname{kip}^{\mathrm{h}} \mathrm{a}+\mathbf{p}^{*} \text { ako } \\
=\text { kip }^{\mathrm{h}} \text { ako }\end{array}$ & $\begin{array}{l}\operatorname{kip}^{\mathrm{h}} \mathrm{a}+\text { pako } \\
=\text { kip }^{\mathrm{h}} \text { ako }\end{array}$ \\
\hline Fortis & $\begin{array}{l}\text { kip*a+p pako } \\
=\text { kip*ako }\end{array}$ & $\begin{array}{l}\text { kip*a+tako } \\
=\text { kip*ako }\end{array}$ \\
\hline
\end{tabular}

Figure 3. Lenis in the pair vs. Lenis not in the pair

In sum, the analysis of the ratings indicates that pairs with a laryngeal difference are more acceptable than pairs with a place or a manner difference. When there is a difference in the place feature, the quantity of the difference, i.e. 1 difference (1P) or 2 differences (2LP), does not significantly affect the rating. In addition, fortis/aspirated stops are preferred in the resultant blend when segments from the source words are different only in laryngeal feature. The acceptability of a lenis-aspirated or lenis-fortis pair is higher than an aspirated-fortis pair.

\section{Discussion}

Based on the results, if segments are not identical, there are clear differences in acceptability between pairs with a laryngeal feature specification difference and pairs with a place or manner feature specification difference (also, see Oh, 2007). Given 1L, 1P, and $1 \mathrm{M}$ are all different in one feature, the number of features (1or 2 differences) cannot explain the data, but the type of features (laryngeal, place or manner) is crucial. In this section, I will show that the Korean alternation grammar trained in the Max-ent grammar tool fits the result from the nonce word study better than other models based on similarity.

5.1 Korean alternation grammar One possible explanation for this result is that patterns shown in Korean imperfect overlapping are similar to patterns shown in Korean alternation grammar. Korean has alternations in all three features: place, manner, and laryngeal features. However, laryngeal features are less restricted because they can alternate in onset position in addition to coda neutralization, whereas place (Jun 1995) and manner (Davis \& Shin, 1999) features alternate in coda positions. This is related to the current study because imperfect overlap in the experiment was always in an onset segment.

As we can see from example (13), the place feature, manner feature, and laryngeal feature alternate in coda position. In $/ \mathrm{mit}-\mathrm{ko} /, / \mathrm{t} /$ became $/ \mathrm{k} /$ because of the assimilation to the following consonant $/ \mathrm{k} /$. Also, in /top-nal/, /p/ undergoes a change in manner to $/ \mathrm{m} /$ because of the following nasal consonant $/ \mathrm{n} /$. Korean shows coda neutralization, so only lenis stops can occupy the coda position as in $/ \mathrm{pat}^{\mathrm{h}} /$ and $/ \mathrm{pak} *$. On the other hand, in onset position, only laryngeal feature alternate (there are a few exceptions such as lateralization of nasal stops in onset position or place assimilation of two nasal stops, but only cases including oral stops are considered in this paper). Verb particle/-ta/ can be either a lenis, aspirated, or fortis stop based on the preceding segments. There is no alternation when it is preceded by a vowel, and it alternates with its aspirated counterpart when it is preceded by $/ \mathrm{h} /$. A lenis stop becomes a fortis stop when it is preceded by another stop.

Phonological alternation in Korean

\begin{tabular}{|c|c|c|c|}
\hline \multirow{2}{*}{ Place (assimilation) } & \multirow{2}{*}{ Manner (nasalization) } & \multicolumn{2}{|l|}{ Laryngeal } \\
\hline & & coda (neutralization) & onset \\
\hline $\begin{array}{l}\text { mit-ko } \rightarrow[\text { mikko } \underline{\text { 'bke }} \\
\text { 'believe+and' }\end{array}$ & $\begin{array}{l}\text { top-nal } \rightarrow \text { [tomnal] } \\
\text { 'saw blade' }\end{array}$ & $\begin{array}{l}\text { pat }^{\text {h }} \rightarrow \text { [pat] 'field' } \\
\text { ip } \mathbf{p}^{\mathrm{h}} \rightarrow \text { [ip] 'leaf' } \\
\text { pak } \rightarrow \text { [pak] 'outside' }\end{array}$ & $\begin{array}{l}\text { ha+ta } \rightarrow \text { [hata] 'to do' } \\
\operatorname{coh}+\underline{t a} \rightarrow\left[\cot ^{\text {h}} \text { a] 'to like' }\right. \\
\text { ip }+ \text { ta } \rightarrow\left[i p t^{* a}\right] \text { 'to wear' }\end{array}$ \\
\hline
\end{tabular}


I argue that the grammar used for imperfect overlapping in Korean blends reflects speakers' knowledge of native grammatical alternations. In other words, Korean speakers use abstract grammatical knowledge rather than other similarity sources. This will be validated if the result of the nonce word study can be explained with the grammar independently motivated in Korean phonology.

I trained a Max-Ent grammar on the alternation patterns of Korean using the Max-Ent grammar tool (Wilson, 2006). Once the corpus with frequency and constraints are trained on the Max-Ent grammar, relative constraint weights and a probability of each candidate is generated. The grammar is based on the framework of Harmonic Grammar (Legendre et al., 1990; Smolensky \& Legendre, 2006). Harmonic Grammar (HG) represents the output form with the relative strengths of competing constraints, and constraints have numerical weights. These weights can lead to a ganging effect.

Korean alternation data including the examples above were used to train the grammar with relevant constraints as in (14). All faithfulness constraints are position sensitive (Beckman, 1997), so faithfulness constraints are divided into one for coda and one for onset position. For the laryngeal feature, Identityfeature [+fortis/+aspirated] and Identity-feature [-fortis/-aspirated] are considered to be different (cf. 2001). In onset position, lenis stops can be fortis/aspirated stops, but not the other way around.

(14) Constraints ( $\alpha$ can be either ONSET or CODA)

ID- $\alpha$ [Place]: Assign a violation mark if the place feature of the output in $\alpha_{1}$ differs from the input in $\alpha_{1}$ ID- $\alpha$ [Manner]: Assign a violation mark if the manner feature of the output in $\alpha_{1}$ differs from the input in $\alpha_{1}$

ID- $\alpha$ [ \pm fortis/aspirated]: Assign a violation mark if the \pm fortis/aspirated feature of the output in $\alpha_{1}$ differs from the input in $\alpha_{1}$

Agree [Place]: Assign a violation mark if two adjacent consonants don't agree in place feature

Agree [Manner]: Assign a violation mark if two adjacent consonants don't agree in manner feature

Fortify/aspirate: Fortify/aspirate the lenis stop followed by other lenis stop or glottal fricative $/ \mathrm{h} /$

For the training data, I used examples from previous studies in Korean alternation (Jun, 1995; Davis \& Shin, 1999 among others). All existing alternation forms have a frequency of 1, whereas losing candidates were assigned the frequency of 0 . The Max-Ent grammar tests new forms with weights based on the inputs with frequency. It then makes predictions for new forms. Stimuli from the experiment were also tested in the Max-Ent grammar. The results file shows the probability for each candidate in the stimuli. The results show constraint weights and the harmony score and probability of each candidate. Tableau (15) is an example of the harmonic score and probability of each candidate. The non-overlapping candidates are not included in the tableau for simplicity. They are not optimal because of the Max-segment constraints, and the detailed analysis can be found in Ahn (2014).

When overlap consonants differ only in laryngeal features

\begin{tabular}{|l||c|c|c|c|l|}
\hline $\operatorname{cop}_{1}{ }{ }+\mathbf{p}_{2}{ }_{2}$ uso & $\begin{array}{c}\text { ID-ONS[pl] } \\
(9.6)\end{array}$ & $\begin{array}{c}\text { ID-ONS[+for/asp] } \\
(8.6)\end{array}$ & $\begin{array}{c}\text { ID-ONS[-for/asp] } \\
(0.002)\end{array}$ & $H$ & Probability \\
\hline \hline (a) cop ${ }_{1,2}$ uso & & & -1 & -0.022 & 0.99 \\
\hline (b) cop $\underline{p}_{1,2}$ uso & & -1 & & -8.62 & 0.00 \\
\hline
\end{tabular}

On the other hand, when overlapping consonants differ only in place feature, there is no preference for either labial or alveolar stops as in tableau (16).

(16) When overlap consonants differ only in place features

\begin{tabular}{|l||c|c|c|c|c|}
\hline $\operatorname{cop}_{1} \mathbf{u}+\underline{\mathbf{t}}_{2}$ uso & $\begin{array}{c}\text { ID-ONS[pl] } \\
(9.6)\end{array}$ & $\begin{array}{c}\text { ID-ONS[+for/asp] } \\
(8.6)\end{array}$ & $\begin{array}{c}\text { ID-ONS[-for/asp] } \\
(0.002)\end{array}$ & $H$ & Probability \\
\hline \hline (a) $\operatorname{co} \underline{p}_{1,2}$ uso & -1 & & & -9.62 & 0.5 \\
\hline (b) cot $\underline{t}_{1,2}$ uso & -1 & & & -9.62 & 0.5 \\
\hline
\end{tabular}

The harmonic score and probability of each candidate were used as factors to predict the results. Both harmonic score and probability reached significance $(\mathrm{p}<0.001)$, but probability fit the experiment results 
slightly better than Harmony Score.

The analysis based on the alternation grammar explains why among laryngeal feature differences, fortis-aspirated pairs are rated lower than fortis-lenis or aspirated-lenis pairs in Figure 3. The weights of faithfulness constraints for fortis and aspirated stops are higher than the faithfulness constraints for lenis stops, because in onset position, only lenis stops become fortis or aspirated stops, but not vice versa. It is less preferable to lose the fortis or aspirated feature when they are competing with each other. Korean alternation patterns are consistent with this result in that there is no case of aspirated-fortis alternations.

Why is there a difference between place and laryngeal features in terms of faithfulness? The asymmetry between place features and laryngeal features is found in many languages. Steriade (2001), Lombardi (2001), and Rose and Walker (2004) argue that differences in laryngeal features are less salient than differences in place/manner features. This asymmetry may also be reflected in Korean grammar. The grammar of Korean prohibits alternation in place and manner in onset position. The crucial prediction is whether blends with mismatched segments in coda position would also reflect the regular Korean grammar.

5.2 Feature Counting, Shared-natural classes, and Faithfulness In the current experiment, stimuli were categorized by the number of feature differences: identical, one difference, and two differences. Feature counting showed a significant result in section 4 (Figure 1a), but the model fit is worse than the Korean alternation grammar. The predictions based on the type of features (conditions) also showed a significant result in section 4 (Figure 1b), but they are still worse than the Korean alternation grammar. The similarity based on the shared-natural classes measurement reached significance $(p<0.001)$ and was a better fit than the number of features and conditions, but not as good as the Korean alternation grammar. Table (17) below shows how well each model predicts the results of the experiment.

The fit of each model

\begin{tabular}{|l|l|}
\hline Model & $\begin{array}{l}\text { Fit of the models } \\
\text { (the lower AIC/BIC indicates the better fit) }\end{array}$ \\
\hline \hline Number of features & AIC: 38409, BIC: 38447 \\
\hline Conditions (the type of features) & AIC: 38314, BIC: 38382 \\
\hline Shared-natural classes & AIC: 38279, BIC: 38332 \\
\hline Korean alternation grammar (Max-Ent) & AIC: 38094, BIC: 38147 \\
\hline
\end{tabular}

Unlike other similarity measurements, one of the advantages of the Max-Ent model is that it predicts the best candidate based on probability. It successfully predicts which segment will be chosen between two segments, and this choice reflects the phonological grammar of Korean. Also, it is worth mentioning that the Max-Ent grammar is partly getting a better fit than other models because it has more predictors; it has hand-made faithfulness constraints that reflect the knowledge of the data. In sum, what Korean speakers were using in the nonce word task were language-general faithfulness constraints.

\section{Conclusion}

This paper explores imperfect overlapping in blending, which has been reported in many languages, including Korean, but has not been studied thoroughly. The evidence from the experiment showed that Korean speakers prefer a blend with an overlap of similar segments and a certain segment in the blend, as has been attested with the existing data. Also, imperfect overlapping is not a random process; it is influenced by the phonological knowledge of Korean speakers. Korean speakers use the grammar they know from Korean alternations rather than construction-specific grammar or similarity between segments in the source words.

In addition, the current study focused on the survival of the 'segment,' not the 'feature' itself when two segments coalesced in the resultant blend. A follow-up study can tease these apart, such as the case in which an aspirated stop coalesces with a lenis stop with a different place feature: 'patu $+\underline{\mathbf{k}}^{\mathrm{h}} u k a=$ pat $\underline{a}^{\mathrm{h}} u k a . '$

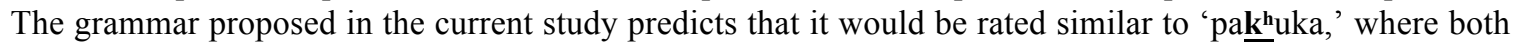
place and laryngeal feature are from the same segment. Further research will determine the answer to the coalescence of two segments with different place and laryngeal features. 


\section{References}

Ahn, Suzy (2014). Faithfulness conflict in Korean blends. University of Pennsylvania Working Papers in Linguistics, 20(1), 1-10.

Algeo, John (1977). Blends, a structural and systemic view. American Speech, 52, 47-64.

Bat-El, Outi (1996). Selecting the best of the worst: the grammar of Hebrew blends. Phonology, 13(03), 283-328.

Bat-El, Outi (2006). Blends. In Keith Brown (ed.), Encyclopedia of Language and Linguistics (2nd edition) (Vol. 2), 66-70. Oxford: Elsevier.

Bates, Douglas, Martin Maechler, Ben Bolker \& Steven Walker (2014). lme4: Linear mixed-effects models using Eigen and S4. R package version 1.1-7. Retrieved from http://CRAN.R-project.org/package=lme4

Becker, Michael \& Jonathan Levine (2010). Experigen: an online experiment platform. Available (April 2013) at https://github.com/tlozoot/experigen.

Beckman, Jill N. (1997). Positional faithfulness, positional neutralisation and Shona vowel harmony. Phonology, 14(1), $1-46$.

Cho, Hyesun (2012). Statistical learning of Korean phonotactics. Studies in Phonetics, Phonology, and Morphology, $18(2), 339-370$.

Davis, Stuart \& Seung-Hoon Shin (1999). The syllable contact constraint in Korean: An optimality-theoretic analysis. Journal of East Asian Linguistics, 8(4), 285-312.

Frisch, Stefan A., Janet B. Pierrehumbert \& Michael B. Broe (2004). Similarity avoidance and the OCP. Natural Language \& Linguistic Theory, 22(1), 179-228.

Gries, Stefan Th. (2004). Isn't that fantabulous? How similarity motivates intentional morphological blends in English. In Michel Achard \& Suzanne Kemmer (eds.), Language, culture, and mind, 415-428. Stanford: CSLI Publications.

Hong, Sung-Hoon (2005). An optimality theoretic analysis of English blends. Korean Journal of Linguistics, 30(3), 551-582.

Jun, Jongho (1995). Perceptual and articulatory factors in place assimilation: An Optimality Theoretic approach. (Doctoral Dissertation), UCLA.

Kelly, Michael H. (1998). To "brunch" or to "brench": Some aspects of blend structure. Linguistics, 36(3), 579-590.

Legendre, Géraldine, Yoshiro Miyata \& Paul Smolensky (1990). Harmonic grammar: A formal multi-level connectionist theory of linguistic well-formedness: An application Proceedings of the Cognitive Science Society, 884-891. Lawrence Erlbaum.

Lehrer, Adrienne (1996). Identifying and interpreting blends: An experimental approach. Cognitive Linguistics, 7(4), 359-390.

Lombardi, Linda (2001). Why Place and Voice are different: Constraint-specific alternations in Optimality Theory. In Linda Lombardi (ed.), Segmental phonology in Optimality Theory: Constraints and Representations, 13-45. Cambridge University Press.

McCarthy, John J. \& Alan Prince (1995). Faithfulness and reduplicative identity. In Jill Beckman, Laura Walsh \& Suzanne Urbanczyk (eds.), University of Massachusetts Occasional Papers 18: Papers in Optimality Theory, 249384. Amherst, MA: GLSA Publications.

Oh, Mira (2007). Perceptual similarity in telephone numbers [In Korean]. Korean Journal of Linguistics, 32, 471-494.

Pater, Joe (2001). Austronesian nasal substitution revisited: what's wrong with *NC (and what's not). In Linda Lombardi (ed.), Segmental phonology in Optimality Theory: Constraints and Representations, 159-182. Cambridge University Press.

Piñeros, Carlos-Eduardo (2004). The creation of portmanteaus in the extragrammatical morphology of Spanish. Probus, $16(2), 203-240$.

R Core Team (2013). R: A language and environment for statistical computing. R Foundation for Statistical Computing. Vienna, Austria. Retrieved from http://www.R-project.org/

Rose, Sharon \& Rachel Walker (2004). A typology of consonant agreement as correspondence. Language, 80(3), 475531.

Shaw, Katherine E., Andrew M. White, Elliott Moreton \& Fabian Monrose (2014). Emergent faithfulness to morphological and semantic heads in lexical blends. In John Kingston, Claire Moore-Cantwell, Joe pater \& Robert Staubs (eds.), Proceedings of the Annual Meetings on Phonology, Washington, DC: LSA.

Smolensky, Paul \& Géraldine Legendre (2006). The harmonic mind: From neural computation to optimality-theoretic grammar. Cambridge, MA: MIT Press.

Steriade, Donca (2001). The phonology of perceptibility effects: the P-map and its consequences for constraint organization. Ms. UCLA.

Wilson, Colin (2006). Learning phonology with substantive bias: An experimental and computational study of velar palatalization. Cognitive science, 30(5), 945-982. 